\title{
PRESENTE VIVIDO NO PASSADO E A SER VIVIDO NO FUTURO
}

\author{
Dedico estas palavras a Tom Andersen
}

CÉLIA BORBA

Assistente social a ocasião do convite de Helena Maffei Cruz para participar do livro organizado em 2017 para homenagear Tom Andersen no décimo aniversário de sua morte, fui tocada pelo desejo de participar do capítulo que seria feito por um conjunto de pessoas. Embora não tenha conseguido produzir o texto, o desejo permaneceu vivo, como a alegria que sinto agora em pensar em cada palavra que compõe este singelo texto.

No final de 2017 em função da legislação vigente que regulamenta a parceria das Organizações da Sociedade Civil (OSC) com o Estado, tive que fazer um novo Plano de Trabalho durante dez dias e o meu empenho era apresentar um serviço propositivo e inovador que envolvesse os usuários e trabalhadores. Apresento um recorte que foca a estrutura física e técnica, mas que reverberou a participação de todos.

Trabalho na área da Assistência Social, em um Centro de Convivência para Criança e Adolescentes, com o nome fantasia de Centro para Crianças e Adolescentes (CCA) - Broto Cidadão, com um convênio para o público de sessenta crianças e adolescentes, localizado no distrito de Santo Amaro, zona sul da cidade de São Paulo, sendo a OSC GAIA responsável pela parceria.

Historicamente a Assistência Social nasceu e se desenvolveu com práticas de caráter assistencialista e sob o olhar empírico, ofertando a prestação do serviço como ajuda momentânea sem o compromisso da superação da vulnerabilidade social do indivíduo.

Com o advento da Lei Orgânica da Assistência Social (LOAS), a Assistência Social passa a compor uma política de fato do Direito que, ao longo do tempo, por meio das Normativas e Resoluções, culminou no Sistema Único de Assistência Social (SUAS), que direciona as obrigações do Estado e da Sociedade Civil tendo como base das atenções o destino do trabalho na Centralidade Familiar e na Territorialização. Com isto, fez-se e se faz necessário o rompimento do estigma amador tanto na operacionalização técnica como no linguajar assistencialista, assegurando a comunicação de forma objetiva e compreensiva.

É notório, no entanto, que a efetivação plena do SUAS pressupõe decisão Política de Estado e um efetivo Controle Social, mas são necessárias, sobretudo, compreensão e execução do trabalhador da Assistência Social na operacionalização do fazer profissional in loco, desenvolvendo ações coletivas e propositivas que promovam a autonomia e emancipação do usuário, com vista ao protagonismo social pautado no censo crítico e decisões firmadas de forma democrática, respeitando as diversidades, tornando-as fontes de sabedoria e solidariedade. 
Nesse sentido, o espaço físico do CCA, uma casa alugada, aos poucos foi se adaptando com reformas para atender às exigências do contrato para desenvolver o serviço, porém, os lugares da execução das atividades/propostas eram sempre referidos ao lugar da casa, como a sala, o quartinho, a cozinha, o quintal.

Frente aos atuais conceitos da Política da Assistência Social, agregados aos cursos e formações com vista ao aperfeiçoamento do saber técnico, comecei a refletir e ressignificar cada cômodo da casa e as propostas realizadas no local, e neste diálogo interno veio-me a frase de Tom Andersen que me acompanha: "as palavras não são inocentes", o que, para mim, também se estende ao significado dos objetos que estão à disposição do trabalho social.

Iniciei ressignificando o lugar da casa onde cada família se organiza conforme seus costumes, pelo lugar do trabalho privado de caráter público. Sendo assim, os cômodos passaram a ser considerados espaços.

Avancei no pensamento e, para caracterizar a funcionalidade dos espaços, propus sua nomeação, inspirada na exposição do fotógrafo Douglas Mansur "Mãos que Transformam o Mundo" - homenageando algumas personalidades e pensadores que nos movem e dão sentido ao fazer profissional do cotidiano do CCA.

Faço menção aos colaboradores do GAIA que contribuíram com a nomeação de alguns espaços.

A sala passou a ser Espaço Paulo Freire, para acolhimento coletivo.

O quarto passou a ser Espaço Cora Coralina, para as propostas de acolhimento individual e familiar.

O quarto pequeno passou a ser Espaço Clarice Lispector, para almoxarifado de materiais pedagógicos.

O jardim passou a ser Espaço Chico Mendes, para as propostas ligadas a terra.

O quintal da frente passou a ser Espaço Renata Meirelles, para as propostas recreativas.

O quintal de trás passou a ser Espaço Luísa Mahin, para as propostas festivas e celebrativas.

A cozinha passou a ser Espaço Alex Atala, para cozinha e dispensa de alimentos.

O refeitório passou a ser Espaço Zilda Arns, para as propostas de alimentação, oficinas culinárias e jogos de mesas e Artes.

A gerência, por fim, passou a ser Espaço Tom Andersen, a quem dedico estas palavras e a minha singela homenagem.

O ano de 2018 iniciou com algumas situações administrativas não tão prazerosas, e na perspectiva de extrair o que se pode aprender com as intercorrências, segui dando o melhor de mim e só em meados de agosto consegui dar continuidade na materialização das identificações dos espaços.

Vale ressaltar que o Plano de Trabalho, em relação às atividades com os usuários, foi executado normalmente e, entre essas atividades, as crianças e adolescentes passaram por uma experiência de pintura com folha de sulfite e tinta guache de forma livre.

Com a proposta de nomear as identificações dos espaços, solicitei à equipe técnica operativa que propusesse uma atividade para pintar nove telas com tintas de tecido de forma livre, porém que fossem formados grupos para pintar cada tela.

O processo aconteceu pautado no diálogo entre os envolvidos para as negociações das cores, traços e mediações dos conflitos, tendo resultados além das pinturas, que ficaram surpreendentes. 
Paralelamente a esta atividade, fiz uma breve pesquisa biográfica sobre os homenageados para apresentá-los e também dar sentido à motivação da nomeação dos espaços. Procurei sintetizar o histórico e junto da imagem de cada personalidade uma frase autoral.

Os históricos e as imagens foram impressos e colados nos quadros e os usuários novamente foram envolvidos. Solicitei para a equipe técnica operativa que propusesse a atividade, que fossem formados nove grupos nos dois períodos e que entregassem a pesquisa para cada grupo juntamente com o quadro correspondente, orientando-os para que lessem o material e organizassem a forma de apresentação para os demais grupos. Mais uma vez as crianças e os adolescentes foram protagonistas, apresentando os homenageados por meio de jogral, leituras compartilhadas e teatro. Concluíram com a colocação dos quadros em cada espaço de referência.

Para finalizar este texto, retorno às pesquisas biográficas, apresentando somente a de Tom Andersen, a quem presto esta homenagem. Antes de começar a escrever, pensei em várias hipóteses, como ler sobre Tom, pesquisar nas redes sociais, telefonar para as professoras do Projeto Triângulo Austral, mas me pus em frente ao computador e comecei a relembrar o processo através do qual Tom Andersen faz parte da minha história e assim o apresentei.

\section{Tom Andersen}

Nascimento: 02 de maio de 1936, Oslo, Noruega

Falecimento: 15 de maio de 2007

Tom Andersen faz parte da minha história, por meio do Projeto Triângulo Austral, uma parceria das Universidades de Tromso - Noruega, Universidade Nacional de Lanus - Argentina e Instituto Familiae - Brasil.

Este projeto foi fruto de um olhar que Tom Andersen teve para a dupla de profissionais (Marilia de Freitas Pereira e Helena Maffei Cruz) a partir de uma apresentação no Congresso da Associação Internacional de Terapia Familiar, em Oslo, no ano 2000, um trabalho realizado em um albergue para moradores em situação de rua em São Paulo.

Tom ficou tão encantado que acentuou o seu desejo de consolidar um Projeto na América do Sul, com profissionais cujo trabalho com pessoas em situação de vulnerabilidade social e/ou emocional ele conhecia e admirava. Assim nasceu o Projeto Triângulo Austral entre os países Brasil, Paraguai e Argentina, sendo contemplados 12 profissionais/estudantes de cada país, estando eu entre esse grupo.

Pelos relatos que ouvia sobre Tom Andersen, no meu imaginário ele seria uma pessoa altamente culta e de difícil acesso. O meu primeiro contato foi na semana em que o curso foi realizado no Brasil, onde ficamos hospedados, no extremo sul da cidade de São Paulo, em uma região rural.

$O$ encontro com ele foi marcante pela sua simplicidade enquanto pessoa e na transmissão dos seus conhecimentos, os quais procuro ouvir no meu cotidiano.

Quero compartilhar também que o curso ofertado por intermédio de Tom Andersen tinha o desejo de que todos os estudantes tivessem pelo menos uma vez a experiência de viajar para outro país para ampliar seus conhecimentos, assim como ele teve, aprendendo, nas suas visitas, a gostar da cultura, culinária e música brasileiras. 
Entre as recordações que me fazem lembrar de Tom estão a música Trem das Onze, seu caminhar na estrada de terra e o seu pedido para que na alimentação houvesse frutas como banana.

As viagens Internacionais aconteceram e eu, pela primeira vez, viajei de avião para o encontro na Argentina e a segunda para o encontro no Paraguai.

Tom Andersen tinha outro desejo: desde seus primeiros workshops fora de seu país, criou um fundo financeiro que tinha como um dos objetivos doá-lo para os estudantes dos projetos que desenvolvia, com o único pedido de que se o estudante desenvolvesse um projeto social, ele gostaria de saber.

Assim mais uma vez fui beneficiada, e parte deste recurso foi utilizada por um grupo que desenvolveu um projeto no extremo sul da cidade de São Paulo, com diversos profissionais de organizações socais; com outra parte comprei meu primeiro computador, que acabei doando para o meu atual trabalho e que por um bom tempo nos serviu.

Tom Andersen, não chegou a ter o conhecimento do nosso feito em vida, mas ficou para mim a sua generosidade. Hoje ele está presente na minha história de vida, e para homenageá-lo dedico o meu espaço de trabalho ao seu nome.

A sala da Gerência leva o nome de Tom Andersen e esta historia foi e é compartilhada com a equipe de trabalho e com as crianças usuárias do serviço.

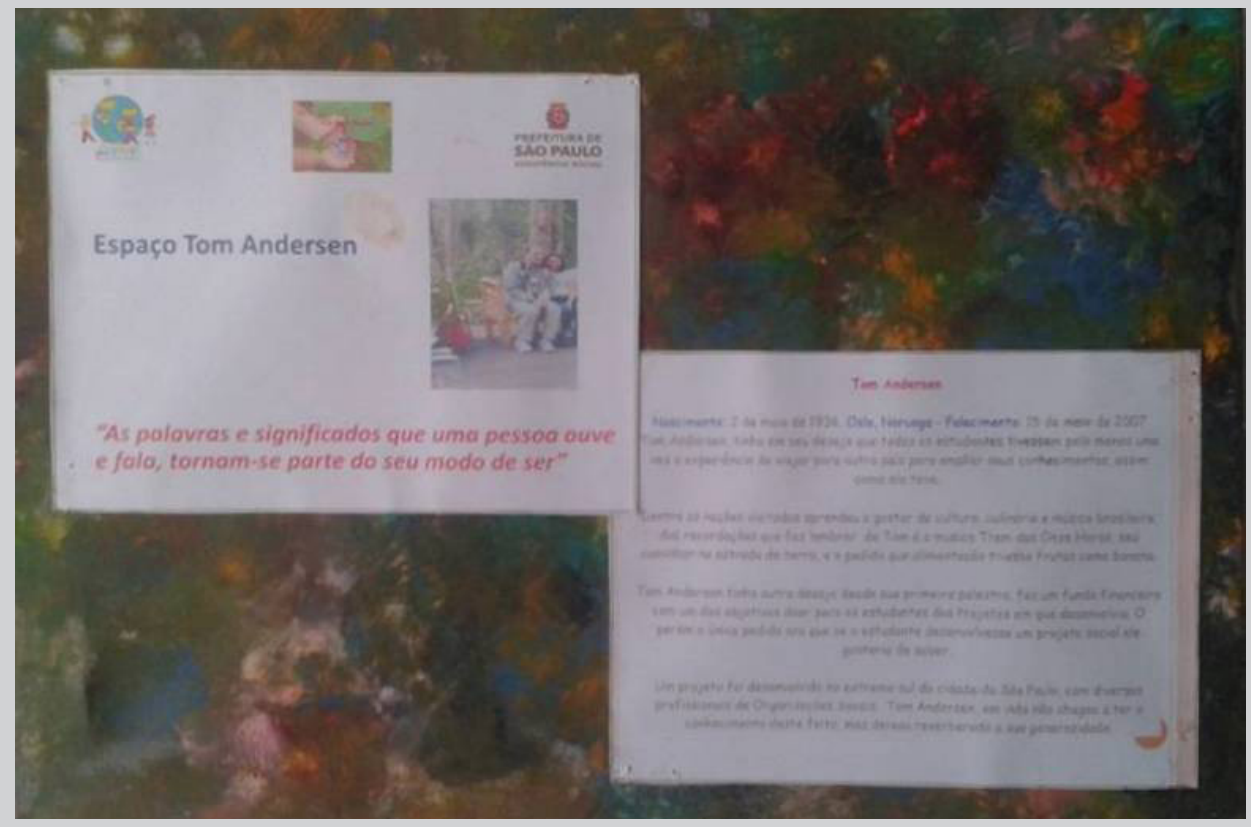

